América Latina: de las esperanzas emancipadoras a la reconfiguración de las derechas Carlos Ciappina

Tram[p]as de la comunicación y la cultura (N. ${ }^{\circ} 83$ ), e033, abril-septiembre 2018

ISSN 2314-274X | https://doi.org/10.24215/2314274Xe033

http://perio.unlp.edu.ar/ojs/index.php/trampas

FPyCS | Universidad Nacional de La Plata

La Plata | Buenos Aires | Argentina

\title{
AMÉRICA LATINA: \\ DE LAS ESPERANZAS EMANCIPADORAS \\ A LA RECONFIGURACIÓN DE LAS DERECHAS
}

LATIN AMERICA:

FROM THE EMANCIPATORY HOPES

TO THE RECONFIGURATION OF THE RIGHTS

\author{
Carlos Ciappina \\ cciappina@perio.edu.unlp.ar \\ http:/ / orcid.org/0000-0002-4780-9435
}

\section{Instituto de Estudios Comunicacionales en Medios, Cultura y Poder Aníbal Ford Facultad de Periodismo y Comunicación Social Universidad Nacional de La Plata | Argentina}

\begin{abstract}
Resumen
Abstract

El autor desarrolla en este texto el The author develops in this text the resurgimiento de las derechas en América Latina, los modos en los que acceden al poder $\mathrm{y}$ las implicancias que esto tiene para el futuro de la democracia en la región, luego del período de despliegue de los gobiernos nacional-populares de principios del siglo XXI. resurgence of the rights in Latin America, the ways governments come to power and the implications for the future of democracy in the region are considered, after the period of deployment of national-popular governments of the beginning of the 21 st century.
\end{abstract}

Palabras clave | democracia, neoliberalismo, gobiernos nacional-populares Keywords | democracy, neoliberalism, national-popular governments 


\section{AMÉRICA LATINA:}

DE LAS ESPERANZAS EMANCIPADORAS

A LA RECONFIGURACIÓN DE LAS DERECHAS

Por Carlos Ciappina

Hace apenas unos años, en 2010, parecía que finalmente comenzaba a realizarse el viejo sueño de los libertadores y los emancipadores latinoamericanos. En la Argentina, un gobierno emparentado con la tradición peronista había sucedido al anterior impulsando reformas importantes en materia económica y social; en Bolivia, gobernaba Evo Morales, el primer indígena presidente desde la Independencia Boliviana; en Venezuela, Hugo Chávez Frías mantenía firme el timón de la Revolución Bolivariana; en Paraguay, gobernaba Fernando Lugo, el primer presidente electo por el voto verdaderamente libre que no provenía del partido colorado; en Uruguay, asumía su mandato el ala más radicalizada del Frente Amplio, con José Mujica; en Ecuador, el gobierno de Rafael Correa se sostenía firme; en Brasil, Lula Da Silva terminaba su exitoso mandato y era votada Dilma Rousseff, ambos del Partido Trabahlista; en Nicaragua, gobernaba el Frente Sandinista, de la mano de Daniel Ortega.

Con sus diferencias geográficas, territoriales, de recursos y de modos de construcción politica, estos gobiernos coincidieron en un conjunto de planteos y de lógicas de gestión: recuperación de la soberanía económica nacional, ampliación de la esfera de intervención del Estado en la economía, combate contra la indigencia y la pobreza con programas de alcance masivo y/o universal, desendeudamiento externo, ampliación de derechos civiles, sociales y económicos, para las mayorias (en muchos casos, indígenas, como en Bolivia y en Paraguay) y para las minorías (indígenas y también de diversos colectivos de género, en países como Uruguay o la Argentina). 
Al mismo tiempo, estos procesos coincidentes en los grandes ejes emancipatorios desde el punto de vista social y económico, comenzaron a articularse internacionalmente. A la rotunda negativa al ALCA (Área de Libre Comercio de las Américas), el proyecto de los EEUU para unificar el continente americano bajo su comando, estos países y gobiernos (que llamaremos, aún reconociendo su heterogeneidad, "nacional-populares") crearon nuevas formas de integración: el TPC-ALBA (Alianza Bolivariana para los Pueblos de Nuestra América - Tratado de Comercio de los Pueblos), la UNASUR (Unión de Naciones Suramericanas), la ampliación del MERCosur (Mercado Común del Sur) y la CELAC (Comunidad de Estados Latinoamericanos y Caribeños). Por primera vez, la política exterior latinoamericana se organizó desde la independencia en organizaciones de integración que excluían de la toma de decisiones a los EE.UU. (a tal punto que la Organización de los Estados Americanos [OEA], el tradicional organismo panamericano de influencia norteamericana, quedó casi sin legitimidad).

En la actualidad, ese panorama alentador de círculo virtuoso entre la integración y la emancipación interna de los países latinoamericano está seriamente puesto en duda. ¿Los motivos? El retorno de las derechas (así, en plural, pues, como veremos, no se comportan todas de la misma manera). En este sentido, podemos hablar de un campo sociopolítico en disputa, como expresión de proyectos sociales hegemónicos enfrentados a proyectos contrahegemónicos.

Hay una larga tradición en el estudio de las derechas en América Latina. Los estudios clásicos de la década del sesenta vinculaban las derechas a la consolidación de las economías agrominero-exportadoras y a la extensión de la clase terrateniente y su expresión política: la república oligárquica. Esta identificación con las élites terratenientes se completaba con un análisis que las vinculaba a los intereses de las naciones colonialistas (Gran Bretaña, Francia) y, a partir de la Primera Guerra Mundial, a la expansión norteamericana.

La consecuencia de esta articulación entre los intereses terratenientes / mineros y las potencias externas conllevaba una política que -aunque republicana en la retórica - desconfiaba profundamente de la democracia y, en última instancia, recurría a las Fuerzas Armadas para interrumpir 
procesos de modernización y de democratización. La resultante de este comportamiento de las derechas tradicionales fueron las dictaduras latinoamericanas de los años setenta y ochenta del siglo $\mathrm{xX}$, que articularon intereses elitistas nacionales y extranjeros mientras reprimían la movilización social y politica.

El regreso de la derechas a la política latinoamericana en el siglo XXI tiene, sin embargo, un componente novedoso: descartada la opción del Golpe de Estado clásico, mediante el cual las fuerzas armadas obturaban la permanencia de un gobierno democrático / popular, las derechas se han propuesto retomar el control del Estado en una mezcla de procedimientos de variado tipo: el golpe institucional de la mano del Congreso (el caso de Paraguay y de Brasil), el triunfo dentro del sistema electoral (como en la Argentina), los intentos de sublevación civil para derrocar lisa y llanamente al ejecutivo (la rebelión de la media luna fértil contra Evo Morales o, la más actual, del caso Venezolano).

En este intento de retorno a la conducción del Estado, las derechas latinoamericanas no están solas: cuentan, en todos los casos, con una alianza de nuevo cuño: el entramado entre el Poder Judicial y el poder de los medios de comunicación hegemónicos. Esta trilogia (poder económico, sistema judicial y medios monopólicos de comunicación) funciona en un doble sentido: por un lado, responde a las orientaciones y a las demandas de la derecha en el proceso de deslegitimar a los gobiernos nacional-populares; por el otro, y al mismo tiempo, cuando la derecha asume el poder, actúa como un bloque que provee un blindaje judicial y mediático para llevar adelante las medidas de recomposición neoliberal.

Este artículo se propone analizar, de manera comparativa, tres experiencias: el caso venezolano y los intentos de derrocamiento del gobierno democrático, el retorno de la derecha brasileña vía un golpe institucional y el caso argentino de retorno democrático de la derecha conservadora. Fundamentamos esta elección en que Venezuela, Argentina y Brasil compartieron el despliegue de proyectos nacional-populares democráticos que iniciaron el siglo XXI, promoviendo la emergencia de partidos políticos y de movimientos sociales que instalaron en la agenda política procesos de democratización, de ampliación de derechos y de redistribución de la renta. Y, precisamente, estos tres casos nos permiten comprobar los comportamientos de las derechas 
en ese contexto: la elección de una vía de confrontación, en el caso de Venezuela; el golpe institucional, en el caso de Brasil; y el triunfo por la vía electoral, en el caso de la Argentina.

\section{Venezuela: la derecha antidemocrática \\ busca derrocar al presidente legal y legitimo}

La situación actual de Venezuela configura un caso típico de maniobra político-mediática en la que se articulan las derechas económicas nacionales y extranjeras con los medios masivos de comunicación a escala global y con los intereses geopolíticos de los Estados Unidos en América Latina.

En primera instancia, debe señalarse que el problema de base en la realidad política venezolana se produce por los logros del gobierno bolivariano. A partir de la elección de Hugo Chávez Frias (1998), y hasta la actualidad, se ha desarrollado un proceso nacional, popular y democrático (el socialismo del siglo XXI) que ha transformado (para mejor) las condiciones de vida de amplias mayorías de la población venezolana, históricamente invisibilizadas y sumidas en la pobreza estructural. Un país que repartía la renta petrolera entre unas pocas manos y en donde el establishment politico del Pacto de Punto Fijo entre los socialcristianos y los socialdemócratas (con exclusión taxativa del Partido Comunista) construía una democracia para las minorias.

En estos últimos diecinueve años, la Revolución Bolivariana ha nacionalizado los recursos naturales, otrora en manos de empresas transnacionales; ha mejorado las condiciones populares de salud y de educación; ha sancionado en forma impecable una Constitución Bolivariana que es un ejemplo seguido en varios países del mundo; ha intentado democratizar un sistema de medios monopólico mediante el desarrollo de radios y de medios comunitarios y de la creación de cadenas de medios estatales (inexistentes previamente), junto con ese gran emprendimiento plurinacional comunicacional como Telesur.

Venezuela, además, ha apoyado todas las iniciativas de integración que tuvieran como objetivo afianzar la unión latinoamericana sobre las bases de la independencia y la autonomía frente a las grandes potencias y bloques de poder hegemónicos: el ALBA, la UNASUR, el Pacto Andino, el MERCOSUR y las 
cumbres latinoamericanas de presidentes encontraron a los gobiernos de Chávez y de Nicolás Maduro como participantes y promotores activos, aun en relación con presidentes y con procesos politicos de signo contrario al venezolano.

El origen de la crisis politica en Venezuela tiene un nombre y un apellido conocidos: se llama Mesa de Unidad Democrática. Algún desprevenido podría imaginar que con ese nombre los objetivos políticos de la Mesa de Unidad son los de proteger la democracia en Venezuela; sin embargo, la experiencia histórica reciente señala que esta Mesa de Unidad es el nombre que se autoimponen los actores sociales y políticos menos democráticos de ese país. La derecha venezolana que se nuclea en esta Mesa "Democrática" tiene un solo propósito político: expulsar del poder, antes de que finalice su mandato, al presidente Maduro. Es decir, la Mesa Democrática es, en realidad, la que intenta promover el Golpe y derruir la democracia venezolana.

En verdad, el comportamiento político de la derecha venezolana siempre apostó por el golpe institucional. En abril de 2002, ya consagrada la Constitución Bolivariana, Fedecámaras (un conglomerado de empresas nacionales y multinacionales) junto con los sindicatos de derechas y, muy especialmente, con los medios de comunicación masivos venezolanos y norteamericanos llevaron a cabo un Golpe de Estado que alcanzó a neutralizar al presidente Chávez por unas horas y a promover una asunción presidencial (la del empresario Pedro Carmona) típica de las dictaduras latinoamericanas. La evidente complicidad norteamericana hizo más explícito el carácter reaccionario de la movida. La movilización popular, el rechazo de la mayoría de los países latinoamericanos y la reacción politica del presidente Chávez, apoyado por las FF.AA., abortaron ese Golpe de Estado.

A partir de ese momento, la derecha venezolana se mantuvo siempre en una doble vía política: la participación en los procesos electorales y la búsqueda de un nuevo Golpe de Estado. Una agenda perfectamente antidemocrática, que ve al proceso electoral solo como una herramienta de corto plazo y que considera el derrocamiento del presidente (Chávez en su momento, Maduro en la actualidad) el único objetivo de su actividad política. 
En 2004, la derecha venezolana convocó a las primeras "guarimbas", grupos de acción violenta que ocupan las calles, destrozan vidrieras, interrumpen el transito, utilizan armas de fuego y obligan a los negocios a cerrar. Estas primeras acciones directas antidemocráticas dejaron, en ese momento, un saldo de cincuenta muertos y más de cien heridos.

El 15 de abril de 2013, el excandidato a la presidencia por la derecha, Henrique Capriles, llamó a lo que denominó "desatar la arrechera" (la bronca) en las calles. El resultado: el asesinato de once personas. Un año después, en febrero de 2014, los líderes opositores llamaron a ocupar las calles en lo que denominaron "la salida»: una movilización que tenía, explícitamente, el objetivo de derrocar al gobierno constitucional. Para que se entienda claramente: los líderes de la derecha llamaron a una movilización con el explícito objetivo de promover la violencia y derrocar a Maduro. Cuarenta y tres muertos y ochocientos heridos fue el saldo de este nuevo intento golpista. El líder opositor, Leopoldo López, fue juzgado y condenado por la justicia venezolana por su responsabilidad en este intento sangriento de Golpe. Todavía embarcada en el derrocamiento del presidente, la derecha convocó en octubre de 2016 a una "toma de Venezuela", con el evidente propósito de expulsar al gobierno democrático.

En un intento por reconducir a la oposición al funcionamiento democrático, el gobierno de Maduro convocó, a fines de 2015, a una Mesa de diálogo con la intervención del Vaticano y de la UNASUR como garantías; pero la Mesa de Unidad Democrática entendia a esta Mesa solo como un nuevo espacio para derrocar a Maduro; y al no avanzarse en este sentido, se retiraron. En este trasfondo de una derecha antidemocrática, golpista y para nada comprometida con los procesos legales, es en el que debe encuadrarse la crisis que se ha desatado en Venezuela.

En la actualidad, la derecha apuesta a profundizar el conflicto de poderes (en Venezuela, los poderes constitucionales son cinco: el poder ejecutivo, el poder legislativo, el poder judicial, el poder ciudadano y el poder electoral). Nuevamente, el proceso electoral es tomado solo como una herramienta que puede utilizarse para profundizar la búsqueda de un golpe institucional. En las elecciones de medio término de 2015 la Mesa de Unidad Popular triunfó y logró la mayoría en uno de los cinco poderes (el parlamento unicameral). 
En cualquier país democrático, con el triunfo de la oposición se inicia un periodo de cohabitación entre gobierno y oposición, pero la derecha venezolana le aplicó a su mayoría en el Parlamento su lógica golpista: fue una herramienta más en el viejo proyecto de derrocar al presidente elegido democráticamente. Los tres diputados electos de la Mesa de Unidad Democrática por el estado de Amazonas lo fueron en un proceso de fraude electoral. El Parlamento, dominado por la derecha, desestimó los reclamos de no tomarles juramento a los diputados hasta que se expidiera el Poder Electoral sobre las acusaciones de fraude. Alli intervino el Tribunal Superior de Justicia (la Corte Suprema de Venezuela) y declaró que si el Parlamento no reveía las tomas de posesión sospechadas de fraude habría una declaración de desacato. Así se desata este conflicto que involucra a los cinco poderes del Estado, cuatro que sostienen la legalidad democrática y uno (el Parlamento en manos de la derecha) que sostiene (contra la opinión del Tribunal Superior de Justicia) la elección por fraude de tres diputados.

Llegamos, así, a la situación actual: cuando el Tribunal Superior de Justicia, en uso de sus atribuciones, declaró que a raíz del desacato el Parlamento carece de legalidad. Era la medida que la derecha buscaba desde las elecciones de 2015.

A partir de ese momento, los gobiernos de derecha en la región (Estados Unidos, Brasil, Argentina, Colombia, Paraguay) se hicieron eco de la muletilla de los grandes medios de comunicación asociados a la ola neoconservadora en América Latina: en Venezuela había un "Golpe de Estado". De repente, gobiernos surgidos de procesos destituyentes, como el de Paraguay; gobiernos ilegítimos, como el de Brasil; y gobiernos con presos políticos y con violaciones a los derechos de huelga y de reunión, como el de la Argentina, se transformaron en "adalides de la democracia".

Junto con este coro de demócratas de ocasión, ha reaparecido la OEA que, a través de su presidente, Luis Almagro, ha iniciado un proceso de presión y de injerencia externa, de la mano del Departamento de Estado de los EE.UU. y de la derecha venezolana, para iniciar un proceso de "separación" de Venezuela de la OEA por "golpe o autogolpe». Curiosa determinación que este organismo no tomó en el caso de la presidenta Rousseff, del presidente Lugo o del presidente Manuel Zelaya, en Honduras. En fin, la OEA como instrumento de lucha contra los gobiernos populares siguiendo al agenda norteamericana. 
En el plano regional sudamericano, también se han sumado a la estrategia de la derecha antidemocrática los gobiernos de Argentina y de Brasil, que proponen separar a Venezuela del Mercosur, aplicándole la "cláusula democrática". Curioso modo de dictaminar lo que la democracia es: en Brasil, el presidente Michel Temer surgió de un verdadero golpe destituyente; en Paraguay, el presidente Horacio Cartes fue electo luego de la destitución exprés del presidente Lugo; en la Argentina, el gobierno de Mauricio Macri mantiene presos políticos desde el primer mes de su gestión de gobierno.

No hay ningún Golpe ni autogolpe en Venezuela. No se han suspendido los principios democráticos de un gobierno electo impecablemente por el voto popular. Lo único persistente en Venezuela es la decisión de la derecha más reaccionaria de apostar, en forma permanente, por la interrupción ilegal del gobierno nacional, popular y democrático y la determinación de los medios de comunicación hegemónicos en toda América Latina de operar para justificar el fin de la revolución Bolivariana y dar inicio a una revancha oligárquica en toda la linea.

En las elecciones para gobernadores de 2017 el triunfo correspondió a los candidatos del chavismo en dieciocho estados y en cinco estados a la oposición Mesa de Unidad. La estrategia del derrocamiento no funcionó en el caso venezolano: las votaciones demuestran un claro rechazo popular a la derecha y esto explica la imposibilidad de una sublevación popular en contra del gobierno bolivariano.

\section{Brasil: el retorno de la sociedad esclavócrata}

El caso brasileño es la expresión más acabada de la nueva modalidad de Golpe institucional de la derecha latinoamericana. El gobierno del Partido Trabahlista (dos períodos presidenciales de Lula Da Silva y la presidencia de Dilma Rousseff) permitió desarrollar un ciclo de trece años de gobierno nacional-popular. En ese lapso de tiempo la sociedad brasileña consiguió logros inéditos en su historia: 28 millones de brasileños salieron de la situación de pobreza, un crecimiento económico sostenido entre 2003 y 2014 y una ubicación geopolítica de potencia mundial. 
Este proceso de redistribución de la renta y de mejora en las condiciones de vida comenzó a ser atacado desde el Poder Judicial en consonancia con un sistema mediático hiperconcentrado (la Red O Globo) que reproducía y que amplificaba las múltiples denuncias por casos de corrupción.

La estrategia se completó con el inicio de un proceso de empeachment a cargo del Senado. Este proceso finalizó cuando el Senado brasileño destituyó a la presidenta electa, legal y legítima, Dilma Roussef. En aquellas escandalosas sesiones, se apreció (en vivo y en directo) la sobreabundancia de expresiones machistas, racistas y prodictadura de senadores que no pudieron probar ninguna contravención a la ley de la Presidenta electa por el voto popular. Su destitución fue, ni más ni menos, un golpe institucional, ilegal e ilegítimo. No hicieron falta los militares; la ruptura del gobierno votado por millones de brasileños estuvo a cargo de los senadores de la derecha, en consonancia con los diputados, con el sistema judicial y, como una constante en las últimas décadas latinoamericanas, con los medios masivos de comunicación.

Con la asunción de Temer -el vice que, en vez de defender el orden constitucional y el gobierno elegido democráticamente, se sumó, instigó y apoyó el golpe institucional- se inauguró así un período de incertidumbre politica y de inestabilidad institucional que seguramente continuará hasta nuevas elecciones. Sin embargo, esta inestabilidad y esta incertidumbre política tienen objetivos a muy largo plazo: ser la herramienta para un intento de cambio profundo en la sociedad brasileña, profundizar las políticas neoliberales y desestructurar el estado construido durante los gobiernos de Lula y de Rousseff.

Lejos de tratarse de una movida improvisada o desesperada de la derecha brasileña, el gobierno de Temer, aún con su escaso tiempo y con su nula posibilidad de continuar por las vias del voto popular, demuestra que el objetivo del Golpe institucional contra Rousseff estaba claro para el establishment, más allá o más acá de los disparatados discursos senatoriales o de las descabelladas fábulas de la Red O Globo: el objetivo del golpe fue cambiar en profundidad la matriz societal que el Partido Trabhalista estaba consolidando en Brasil. Y hacerlo mediante un ajuste estructural de las dimensiones del implementado por los argentinos Carlos Menem y Domingo Cavallo (ajuste, que, por diversas razones, no se hizo en Brasil ni en los ochenta ni en los noventa del siglo XX). 
Tres grandes iniciativas demuestran este intento en profundidad por retrotraer a Brasil a las modalidades más cercanas a una esclavocracia que a una democracia moderna.

Un mes después de asumir el cargo en forma ilegítima, el presidente Temer propuso una enmienda constitucional que llamó "Techo de gastos". Con ese eufemismo se escondió la ley que limita el aumento de los recursos estatales a la tasa de inflación oficial del año precedente. La ley (aprobada por diputados y por senadores) limita de este modo la inversión pública por veinte años. Así, si el Estado tiene que incrementar la inversión en Educación y Salud, por ejemplo, solo podrá hacerlo hasta el tope planteado por la inflación del año anterior, despegado de las necesidades reales y concretas de una población con enormes carencias en materia de educación y de salud o desentendido del crecimiento poblacional. El efecto buscado (como en toda reforma neoliberal) es reducir el "gasto" estatal para, supuestamente, mejorar los índices económicos. En la práctica, menor inversión estatal no solo afecta los servicios públicos esenciales, sino que paraliza la obra pública $\mathrm{y}$, por lo tanto, reduce aún más la ya retraída economía.

Tres meses después de asumir el cargo, Temer envió al Congreso un proyecto de Reforma de la Legislación Jubilatoria que propone una modificación profunda. Hasta esta reforma, las mujeres podían jubilarse con 30 años de aportes y los varones con 35, independientemente de la edad. La reforma establece una edad mínima de 65 años (varones y mujeres) y un mínimo de 25 años de aportes. La modificación tiene un claro objetivo fiscal: aumentar la recaudación jubilatoria a través del mantenimiento o la reducción de los pagos a las personas que podrían adherir a la jubilación y de la extensión de la edad para acceder a ella.

En julio de 2017 el Senado aprobó la propuesta de Reforma Laboral de Temer. El sistema laboral brasileño había sido diseñado durante la presidencia de Getulio Vargas (otro gran presidente odiado por la oligarquía brasileña) y se basaba en el principio laboral del pago mensual a los/las trabajadores/as, la estabilidad laboral (excepto motivos fundados e indemnización previa) y la afiliación obligatoria a los sindicatos de cada rama o área. Las leyes laborales de Vargas, sancionadas en 1943, estaban, aún en estos años, vigentes. 
La nueva Ley Laboral (2017) habilita la jornada intermitente, esto es, la contratación por jornada o, inclusive, por hora; también habilita a dividir las vacaciones hasta en tres tramos, la posibilidad de extender la jornada laboral hasta las doce horas diarias y el fin de la obligación a estar agremiado y a pagar el sostenimiento del sindicato (el equivalente a una jornada laboral por año para cada trabajador). La Reforma laboral - que retrocede a la situación de Brasil de antes de la década de 1940- fue elaborada (sí, aunque parezca mentira) por la Confederación Nacional de la Industria y la Confederación Nacional de la Agricultura, esto es, las organizaciones patronales del capital. También recibió el apoyo de la Federación Nacional de Bancos y de los oligopolios mediáticos.

A partir de estos tres pilares se explica el golpe institucional de Temer, que representa la expresión más cruda de las necesidades del gran capital en Brasil.

Un flanco no menor de esta situación de nuestro país vecino es el efecto en el resto de América Latina y, en particular, en la Argentina neoconservadora: ajuste estatal, reforma jubilatoria y flexibilización laboral es, precisamente el paquete de medidas que viene anunciando el gobierno neoliberal argentino. Si el modelo es Brasil, los resultados serán catastróficos.

\section{Argentina: la via democrática hacia el neoliberalismo}

Conscientes de que recurrir a las Fuerzas Armadas y a los golpes brutales típicos de la tradición del siglo XX no tenía margen en la sociedad argentina en general, la derecha argentina se aprestó a dar la batalla para triunfar, por primera vez, en un proceso eleccionario universal y sin fraude. A diferencia de otras derechas latinoamericanas - como el caso de Paraguay, de Honduras y de Brasil (y los intentos actuales de la derecha golpista en Venezuela)-, en nuestro país el cambio de signo político y la derechización se hicieron de la mano de una elección limpia y transparente.

El gobierno surgido de las urnas, sin embargo, considera esa legitimidad de origen y esa legalidad institucional como una muestra clara de su apego "democrático". El problema es que el gobierno de derechas confunde (y cada 
vez más) legitimidad de origen con legitimidad de toda acción de gobierno o de sus instituciones afines. De este modo, cada medida de gobierno o de las instituciones de la república es considerada democrática per se, sin analizar o sin dar lugar al debate sobre su contenido y su sentido. El resultado de esta concepción de una democracia "congelada" en su legitimidad de origen (en el día del triunfo electoral y nada más) es, precisamente, la concepción que justifica medidas y acciones de gobierno que son, cada vez más, incompatibles con la vigencia de la democracia. Nos acercamos, aceleradamente, a la situación descripta para el caso colombiano.

Los primeros dos años han puesto de manifiesto que el actual gobierno argentino tiene una definida política de desconocimiento y de negación de los derechos laborales. La muestra explícita de esa negación es su decisión de no respetar la ley y de no convocar paritarias nacionales en gremios clave (como el de los docentes, por ejemplo).

En los primeros días de su mandato, el gobierno tomó la decisión de "disciplinar" la protesta social y eligió como caso testigo a las/os líderes de la organización social Tupac Amaru. La detención de Milagro Sala es, a todas luces, arbitraria e ilegal, aunque haya sido hecha por instituciones de la república. Este disciplinamiento del derecho a la protesta y del reclamo a las autoridades se profundiza con represiones en situaciones como las de Cresta Roja y la brutal represión a docentes en plena Plaza de Mayo. En este contexto represivo, la protesta de los pueblos originarios (en este caso mapuches) arrojó la primera desaparición forzada de este período de gobierno: la de Santiago Maldonado, un caso que conmovió al país y demostró la profundidad de las politicas represivas del gobierno neoconservador.

Tampoco debe dejarse de lado la toma inconsulta e indiscriminada de deuda externa (con cifras que auguran crisis y privaciones para las generaciones futuras) y el pago al contado a los especuladores que apostaron contra el propio país (los llamados "fondos buitres"), en detrimento del uso de esos recursos para áreas como educación, salud o desarrollo productivo.

Finalmente, la decisión de la Corte Suprema de Justicia de la Nación (que es un poder de la democracia) que acepta la utilización del 2x1 en los casos de represores condenados por crímenes de lesa humanidad (lo que podría liberar, 
anticipadamente, a genocidas mundialmente repudiados) abona y es resultado, a la vez, de este "clima de época" de retroceso democrático en el país; retroceso que los dichos y las acciones xenófobas, machistas y racistas de varios miembros del actual gobierno no dejan de profundizar.

\section{Algunas conclusiones}

La democracia en América Latina está en riesgo. La expresión que asimila cualquier medida de las instituciones republicanas con la idea de que se hacen en democracia es, por lo menos, un error conceptual grave y, por lo más, una estrategia de las derechas para volver legales y legitimas medidas que vulneran los principios más elementales del juego democrático.

No alcanza con votar cada dos o cuatro años, no es suficiente con que funcionen más o menos bien los parlamentos y el poder judicial. Una verdadera democracia no existe solo en las formas sino en los hechos. La pauperización, la explotación laboral y la exclusión social, la represión sistemática y la liberación de genocidas con artilugios legales son, en todos los casos, señales profundas de retroceso democrático y la única forma de modificar esa situación es profundizar los grados de participación popular y no resignar ninguno de los derechos que el pueblo posee como soberano absoluto en un orden democrático.

El campo de disputa está abierto: las derechas han logrado reconfigurarse y, por diversas vías, han accedido al poder sin mediar la intervención militar. Sin embargo, los primeros quince años del siglo XXI no han pasado en vano para las organizaciones populares y para las experiencias nacional-populares en América Latina. En esa puja entre proyectos inclusivos, democráticos y populares, y derechas que promueven desde el Estado la reconstrucción de la exclusión neoliberal se definirá el futuro del continente latinoamericano. 